\title{
COMPARATIVE STUDY OF SINGLE HIGH DOSE ORAL FLUCONAZOLE WITH TOPICAL CLOTRIMAZOLE IN PATIENT WITH LOCALISED PITYRIASIS VERSICOLOR
}

\author{
${ }^{1}$ Dr. G. Sasikala* ${ }^{2}$ Dr. K. Vasanthira \\ ${ }^{1}$ Assistant professor, Department of Pharmacology, Government Kilpauk Medical college , Chennai, India \\ ${ }^{2}$ Professor of Pharmacology, Government Stanley Medical College, Chennai, India \\ *Corresponding Author's Email: sasikala.shri@gmail.com
}

Received 25 Dec 2014; Review Completed 12 Jan 2015; Accepted 13 Jan 2015, Available online 15 Jan 2015

\begin{abstract}
Objective: To compare the therapeutic efficacy, compliance \& cost effectiveness of single high dose of oral fluconazole with topical clotrimazole in patient with pityriasis versicolor

Method: A total number of 60 patients were enrolled for the study. The patients were randomized and allotted into two groups with thirty patients in each groups. The groups were named as GROUP A and GROUP B.All the patient in Group A were treated by applying clotrimazole ointment twice a day for a continuous period of two weeks. This group served as the CONTROL group while patients in GROUP B were treated with single dose of oral fluconazole 400mg. This group served as the STUDY group and the results of this group was compared with the control group.

Results: Sixty patients completed the study..There was statistically significant improvement in clinical and mycological assessment in oral fluconazole group with $\mathrm{p}$ value of $<0.001$ )

Conclusion: Cure rate was higher with oral fluconazole as assessed by clinical \& mycological assessments. No side effect was found with single high dose of oral fluconazole.ore economical compared with that of two week regimen of topical therapy. Patient's compliance also more as it is of single oral therapy.

Key words: Pityriasis versicolor, clotrimazole, fluconazole
\end{abstract}

\section{INTRODUCTION}

Superficial mycoses are most common worldwide. They are believed to affect $20 \%$ to $25 \%$ of the world, s population and the incidence continues to increase ${ }^{1}$. They are caused by dermatophytes. Topical creams and lotions, including, ketoconazole shampoo or cream, selenium sulfide shampoo, terbinafine cream, and ciclopirox cream, are effective in treating Malassezia infections and are usually applied for 2 weeks ${ }^{4}$ Systemic antifungals like $400 \mathrm{mg}$ single dose of oral fluconazole, or Itraconazole/ketaconazole $200 \mathrm{mg}$ /day for 7 days are also effective. ${ }^{1 \mathrm{a}}$ The problem with the use of topical antifungal is the difficulty in applying cream or lotion to a wide body body surface area for longer period. While oral therapy is ideal for this condition which involves the stratum corneum. Patient prefers the convenience of oral antifungal therapy ${ }^{5}$. So it has been decided to compare the efficacy of single dose of oral fluconazole with topical clotrimazole in patients with Pityriasis versicolor.

\section{METHODOLOGY}

This study was conducted as Prospective, Randomized, open labeled, comparative study between November 2011 to August 2012 in the Department of Dermatology, Stanley medical college with prior permission obtained with Institutional Ethics Committee. Good clinical practice was followed as per the Declaration of Helsinki .Sixty patients enrolled for the study with the following inclusion and exclusion criteria after obtaining written informed consent in their own language from those who were willing to participate in this study.

\section{Inclusion criteria}

- Age:18-60 years

- Both sexes

- Newly diagnosed patients with localized pityriasis versicolor

- Patient seeking treatment for the first time.

- Patient who were willing to give informed consent to the study.

\section{Exclusion criteria}

- Patient with extensive lesion

- Age below18years and above 60 years

- Pregnant and lactating women

- Patient with preexisting renal,liver andcardiac illness

- Patient with known history of taking antifungals 
- Patients with immunocomparamised state

A total number of 60 patients were enrolled for the study.The patients were randomized and allotted into two groups with thirty patients in each groups. The groups were named as GROUP A and GROUP B .All the patient in Group A were treated by applying clotrimazole ointment twice a day for a continuous period of two weeks. This group is the CONTROL group while patients in GROUP B were treated with single dose of oral fluconazole $400 \mathrm{mg}$. This group is the STUDY group and the results of this group was compared with the control group.Treatment allocation is as follows.

GroupA _ (Control) \{30 patients_Topical clotrimazole twice a day for 2 weeks $\}$

GroupB _ (Study) \{30patients_Oral fluconazole single dose of $400 \mathrm{mg}$ \}

\section{EVALUATION AND FOLLOWUP}

The effectiveness of treatment was assessed by the following parameters.

1. Clinical efficacy was assessed by the clearance of
a)Desquamation
b)Pigmentation

At the end of $2^{\text {nd }}$ week, $4^{\text {th }}$ week, $6^{\text {th }}$ week. The patient were asked to return the empty tube during the follow up visit period. All the patients were asked to come for follow up at $12^{\text {th }}$ week

2. Mycological clearance was assessed by

a)Skin scraping with $\mathrm{KOH}$ mount

b)Fungal culture

At the beginning and at the end of the study .
The biochemical parameters were assessed at the beginning and at the end of $2^{\text {nd }}$ week of treatment to evaluate any undesirable changes in the functions of the vital organs.

\section{RESULTS}

\section{Demographic statistics:}

Age

In our study the mean age of the patients of both the groups A \& Bwere $30.03 \& 30.33$ respectively which was analysed statistically. There was no significant difference in the age distribution between the groups.

\section{Sex}

In our study sex distribution of the patients of group A\& B were found to be equal. There was no significant difference between the two groups

\section{a) Desquamation}

The mean desquamation at base line was .0 .00 for both the group.By the end of two weeks the mean of group A was $0.83 \&$ Group B was 0.77 which implies there was good improvement in desquamation with Group A compared with Group B .But the $\mathrm{p}$ value was not statistically significant which was 0.527

From fourth week onwards the mean value was higher with Group B and at the end of sixth week the mean value of Group B was 2.83 and in Group A it was2.40 which showed that there was good improvement in desquamation in Group B (P value <0.001)

At the end of 12 week of follow up the mean of Group B was 2.93 and mean of Group A was 2.57 which was statistically significant implies that there was statistically significant improvement with oral fluconazole ( $\mathrm{P}$ value $<0.001)$

Table 1: Shows the degree of desquamation between study groups

\begin{tabular}{|l|l|l|l|l|l|}
\hline \multirow{2}{*}{ Desqumation } & \multicolumn{2}{|l|}{ Topical clotrimazole } & \multicolumn{2}{l|}{ Oral fluconazole } & \multirow{2}{*}{ P value } \\
\cline { 2 - 5 } & Mean & SD & Mean & SD & \\
\hline Baseline & 0.00 & 0.000 & 0.00 & 0.000 & - \\
\hline $2^{\text {nd }}$ week & 0.83 & 0.379 & 0.77 & 0.430 & 0.527 \\
\hline $4^{\text {th }}$ week & 1.80 & 0.484 & 2.20 & 0.407 & 0.001 \\
\hline $6^{\text {th }}$ week & 2.40 & 0.498 & 2.83 & 0.379 & $<0.001$ \\
\hline $12^{\text {th }}$ week & 2.57 & 0.504 & 2.93 & 0.254 & $<0.001$ \\
\hline
\end{tabular}

\section{b) Pigmentation}

Similarly in pigmentation also mean baseline was 0.00 for both the groups.By the end of second week the mean value of pigmentation in Group A was $0.67 \&$ mean of GroupB was 0.47 which implies there was good improvement in pigmentation in GroupA compared with GroupB.But the $p$ value was not statistically significant which was 0.12. But from fourth week onwards the mean improvement in pigmentation was greater in GroupB compared with GroupA and also statistically significant.
At the end of sixth week the mean of Group A was1.83; and Group B was 2.67

( $\mathrm{P}<0.001$ ) implies there was good improvement in pigmentation with oral fluconazole.

At the end of 12 week the mean of pigmentation in GroupB was2.80 when compared with GroupA which showed the mean $2.03(\mathrm{p}<0.001)$ implies during the follow up visit also oral fluconazole showed good improvement. 
Table 2: Shows the degree of pigmentation between study groups

\begin{tabular}{|l|l|l|l|l|l|}
\hline \multirow{2}{*}{ Pigmentation } & \multicolumn{2}{|l|}{ Topical clotrimazole } & \multicolumn{2}{l|}{ Oral fluconazole } & \multirow{2}{*}{ P value } \\
\cline { 2 - 5 } & Mean & SD & Mean & SD & \\
\hline Baseline & 0.00 & 0.000 & 0.00 & 0.000 & - \\
\hline $2^{\text {nd }}$ week & 0.67 & 0.479 & 0.47 & 0.507 & 0.122 \\
\hline $4^{\text {th }}$ week & 1.13 & 0.346 & 1.80 & 0.407 & $<0.001$ \\
\hline $6^{\text {th }}$ week & 1.83 & 0.379 & 2.67 & 0.479 & $<0.001$ \\
\hline $12^{\text {th }}$ week & 2.03 & 0.414 & 2.80 & 0.407 & $<0.001$ \\
\hline
\end{tabular}

\section{Mycological assessment}

Mycological cure which was assessed by skin scraping \&fungal culture. Skin scraping and fungal culture was negative in both the groups at the end of the study.

Thus overall results of our study showed though topical clotrimazole showed better reduction in desquamation \&pigmentation at the end of second week, the results were not statistically significant. Mycological cure was almost similar to oral fluconazole but clinical cure was less compared with oral fluconazole.

\section{Cost effectiveness;}

Pharmacoeconomically single dose of oral fluconazole is cost benefit to the patientscompared to the 2 week course of topical clotrimazole.

\section{DISSCUSION}

\section{a) Desquamatiion}

The mean desquamation at base line was .0 .00 for both the groups. By the end of two weeks the mean of GroupA was 0.83 \& GroupB was 0.77 which implies there was good improvement in desquamation with Group A compared with Group B .But the p value was not statistically significant which was 0.527

From fourth week onwards the mean value was higher with Group B and at the end of sixth week the mean value of GroupB was 2.83 and in Group A it was2.40 which showed that there was good improvement in desquamation in GroupB (P value <0.001)

At the end of 12 week the mean of Group B was 2.93 and mean of Group A was 2.57 which was statistically significant implying that there was statistically significant improvement with oral fluconazole ( $\mathrm{P}$ value $<0.001)$

\section{c) Pigmentation}

Similarly in pigmentation also mean baseline was 0.00 for both the groups. By the end of second week the mean value of pigmentation in Group A was $0.67 \&$ mean of Group B was 0.47 which implies that there was good improvement in pigmentation in Group A compared with Group B. But the p value was not statistically significant which was 0.122

But from fourth week onwards the mean improvement in pigmentation was greater in Group B compared with Group A and also statistically significant $\mathrm{p}$ value. $(\mathrm{p}<0.001)$

At the end of sixth week the mean of Group A was1.83; and Group B was 2.67
( $\mathrm{P}<0.001)$ impliying there was good improvement in pigmentation with oral fluconazole.

At the end of 12 week the mean of pigmentation in GroupB was2.80 when compared with Group A which showed a mean of $2.03(\mathrm{p}<0.001)$ impliying during the follow up visit also oral fluconazole showed good improvement.

\section{Mycological assessment}

Mycological cure which was assessed by skin scraping \&fungal culture .Skin scraping and fungal culture was negative in both the groups at the end of the study.

Thus the overall results of our study showed that though topical clotrimazole showed better reduction in desquamation \&pigmentation at the end of second week, the results were not statistically significant. Mycological cure was almost similar to oral fluconazole but clinical cure was less compared with oral fluconazole at the end of study.

\section{Cost effectiveness;}

Pharmacoeconomically single dose of oral fluconazole is cost of benefit to the patients compared to the 2 week course of topical clotrimazole.

\section{Compliance;}

As fluconazole is single oral dose, the compliance is good with this group.

The other drawbacks of topical therapy is

- Difficulty in applying cream or lotion to a wide surface area twice daily for a continuous period of two weeks.

- Pharmacoeconomically, the treatment regimen is costlier compared with that of single dose of oral fluconazole.

- Patients compliance is also less with this therapy

\section{CONCLUSION}

Oral fluconazole therapy was found to be superior than topical clotrimazole in the treatment of pityriasis versicolor in terms of efficacy and patient compliance and also cost effective for the patients

\section{ACKNOWLEDGEMENTS}

Ethical approval -Obtained

Funding - medication supply by Glenmark India limited.

Conflicts of interest: None 


\section{REFERENCES}

1. Rook volume $2,8^{\text {th }}$ edition page no; 36.10

2. Andrews-Disease of the skin.Clinical dermatology, 11th edition page no302_303

3. Moschella and Hurley dermatology $3^{\text {rd }}$ edition page no $897-89$

4. Fitzpatricks $7^{\text {th }}$ editionvolume2 page no2116_2121

5. Janssen PAJ, Symoens JE: Hepatic reactions during ketoconazole treatment, Am J Med 1983; 74:80-85

6. Shah KA: Efficacy of fluconazole in treatment of tinea versicolor. A study of 25 cases. $24^{\text {th }}$ National Conference of IADVL. Book of Abstracts, 1996; 55.

7. Faergemann J: Treatment of pityriasis versicolor with a single dose of fluconazole. Acta Dermatol Venereol 1992;72:74-75.

8. Michael M .Nelson,Anng.Martin,Michael P Heffernan Fungal diseases with cutaneous involvement,Fitzpatrick's Dermatology in General medicine,2003,vol-2; sixth edition,Mcgraw-hill,Newyork;p_1989.

9. C.K. Jayaram Paniker, Medical microbiology,Ananthanarayanan and Paniker,s Textbook of microbiology,2011,Seventh edition, Orient longman,Chennai;p_613.

10. Thomas G .Mitchell, Medical Mycology ,Jawetz ,Melnick \& adelbergs Medical Microbiology ,1995 $22^{\text {nd }}$ edition.

11. James E. Fitz patrik ,Topical Antifungal agents, Fitz patriks dermatology in general medicine,Vol_2,2003, $6^{\text {th }}$ edition,Mcgraw-hill,Newyork;p_2339.

12. C.K. Jayaram Paniker,

Medical microbiology,Ananthanarayanan and Paniker,s Textbook of microbiology,2011,Seventh edition, Orient longman,Chennai;p_614

13. Michael M .Nelson, Anng. Martin ,Michael P Heffernan Fungal diseases with cutaneous involvement ,Fitzpatrick's Dermatology in General medicine,2003,vol-2; sixth edition,Mcgraw-hill,Newyork;p_2339.
14. C.K. Jayaram Paniker, Medical microbiology,Ananthanarayanan and Paniker,s Textbook of microbiology,2011,Seventh $\quad$ edition, Orient longman,Chennai;p_611.

15. Ellen Jo Baron,LanceR.Peterson,Laboratory Methods in Basic mycology,Bailey \&scotts diagnostic microbiology, $1990,9^{\text {th }}$ edition,Mosby,St.Louis,p_700.

16. Thomas G .Mitchell, Medical Mycology, Jawetz ,Melnick \& adelbergs Medical Microbiology ,1995 22 edition.Lange/Mcgraw-hill,Newyork;P624.

17. Andrew weinStein\&BrainBer man,Topical treatment of common superficial tinea infections, University of Miami School of Medicine,Florida.

18. John Willwrd Rippon,Dermatophytosis and Dermatomycosis,Cutaneous infections,1988,Medical mycology, $3^{\text {rd }} \quad$ edition,W.B.Saunders company,Philadelphia;p_236.

19. K.D.T ripathi,Antifungal Drugs,Essentials of Medical Pharmacology,2010,Sixth edition,Jaypee brothers, New delhi;P-760.

20. H.L.Sharma,K.K.Sharma,Antifungal Drugs,Principles of pharmacology 2011,2 $2^{\text {nd }}$ edition,Paras Medical Publisher,Hyderabad,p 768.

21. John G.Bennet,Anti funal agents, Goodman\&Gilmans The Pharmacological basis of Therapeutics, 2001,10 ${ }^{\text {th }}$ edition,Mcgraw-hill,Newyork;p-1305.

22. PursleyT.J. Blomquist, I.K. abraham, J. andersen, H.F. and Bartley J.A.;Fluconazole - Indused congenital Abnormalities in Three Infants.Clinical Infectious Diseases, 1996,22;336340 .

23. Bernard Idson\&jackL azarus, Semisolids,Leon Lachman, Herbert A Lieberman,Joseph L. Kanig,The Theary and practice Of Industrial Pharmacy, $3^{\text {rd }}$ edition, Varghese publishing House, Bombay;p-534. 